\title{
Bullying e uso de substâncias psicoativas na adolescência: uma revisão sistemática
}

\author{
Bullying and psychoactive substance use during adolescence: \\ a systematic review
}

\author{
Cristina Lessa Horta ${ }^{1}$ \\ Rogério Lessa Horta ${ }^{2}$ \\ Ariela Mester ${ }^{1}$ \\ Daniele Lindern ${ }^{1}$ \\ João Luís Almeida Weber ${ }^{1}$ \\ Daniela Centenaro Levandowski ${ }^{3}$ \\ Carolina Saraiva de Macedo Lisboa ${ }^{1}$
}

${ }^{1}$ Programa de PósGraduação em Psicologia, Pontifícia Universidade Católica do Rio Grande do Sul. Av Ipiranga 6681/ prédio 11/939, Partenon. 90619-900 Porto Alegre RS Brasil. cristinalessahorta@ gmail.com

${ }^{2}$ Departamento de Saúde Mental, Faculdade de Medicina, Universidade Federal de Pelotas. Pelotas RS Brasil.

${ }^{3}$ Programa de Pós-

Graduação em Ciências da Saúde, Programa de PósGraduação em Psicologia e Saúde, Universidade Federal de Ciências da Saúde de Porto Alegre. Porto Alegre RS Brasil.

\begin{abstract}
Bullying and psychoactive substance abuse are prevalent phenomena among adolescents and identified as health problems that may jeopardise the development of all those involved. This systematic review of the literature aims to identify the extent to which involvement in bullying and psychoactive substance use during adolescence are associated, as well as check for differences regarding the social roles of bullying. From the search for empirical articles published between January 2009 and December 2014 in seven electronic databases, 585 records were identified. After the criteria for inclusion and exclusion were applied, the remaining 40 studies were analyzed based on the design, characteristics of the sample and results of the relationship between bullying and psychoactive substance use. Most studies are quantitative and cross-sectional, and they showed mixed samples of boys and girls in the school environment, which was the place where the phenomena are studied by preference. The association between the perpetration of bullying and psychoactive substance use for adolescents of both sexes is revealed. In relation to victimization by bullying, it was not possible to determine the direction and characterization of the relationship with psychoactive substance use.
\end{abstract}

Key words Bullying, drugs, adolescent, systematic review
Resumo Bullying e uso de substâncias psicoativas são fenômenos prevalentes entre adolescentes e apontados como problemas de saúde que podem comprometer o desenvolvimento de todos os envolvidos. Esse estudo de revisão sistemática da literatura pretendeu identificar em que medida o envolvimento em situações de bullying e uso de substâncias psicoativas na adolescência se associam, além de verificar se há diferenças em relação ao papel social do bullying. A partir da busca de artigos empíricos publicados entre janeiro de 2009 e dezembro de 2014, em sete bases de dados eletrônicas, foram identificados 585 registros. Aplicados os critérios de inclusão e de exclusão, restaram 40 estudos que foram analisados a partir do seu delineamento, características da amostra e resultados obtidos sobre a relação entre bullying e uso de substâncias psicoativas. A maioria dos estudos $e ́$ de delineamento quantitativo transversal, com amostras mistas, de meninos e meninas, sendo a escola o local onde esses fenômenos têm sido preferencialmente estudados. Evidenciou-se associação entre perpetração de bullying e uso de substâncias para adolescentes de ambos os sexos. Em relação à vitimização por bullying, não foi possível precisar a direção e a caracterização da relação com o uso de substâncias.

Palavras-chave Bullying, Drogas, Adolescente, Revisão sistemática 


\section{Introdução}

Bullying e uso de substâncias psicoativas são temas recorrentes na literatura científica nacional e internacional, apontados como importantes problemas de saúde, que podem comprometer o desenvolvimento de todos os envolvidos ${ }^{1-5}$. A sua alta prevalência entre adolescentes, somada aos prejuízos associados à sua ocorrência, leva-os a serem considerados como sérios problemas de saúde pública ${ }^{6}$.

Considerado como um tipo de violência interpessoal, que ocorre repetidamente, nota-se no bullying a intenção de ofender (agressão verbal), machucar (agressão física) ou humilhar (agressão relacional) alguém de idade igual ou semelhante, sem motivação evidente, causando dor, angústia e humilhação $0^{7-9}$.

Entre adolescentes norte-americanos, as prevalências de envolvimento em situações de bullying podem variar de $8,9 \%$, referentes ao cyberbullying, até $37,9 \%$ para bullying verbal ${ }^{10}$. Um estudo transcultural, realizado com adolescentes de 40 países, indicou que cerca de 11\% deles são vítimas de bullying ${ }^{2}$. No Brasil, estima-se que $30,8 \%$ dos adolescentes com idade entre $13 \mathrm{e}$ 15 anos já sofreram bullying em algum momento de suas vidas, dos quais 5,4\% quase sempre ou sempre nos últimos 30 dias. Neste mesmo estudo, meninos são referidos como sofrendo ou protagonizando mais bullying do as que meninas ${ }^{8}$.

O envolvimento em situações de bullying, seja como vítima, agressor, vítima-agressor ou expectador, está associado a prejuízos físicos, sociais, afetivos e cognitivos, não só a curto, mas também a longo prazo ${ }^{4}$. Entre os prejuízos causados por este fenômeno, estão: problemas de autoestima, de relacionamento com os pares, dificuldades na aprendizagem, evasão escolar, comportamentos violentos, transtorno de conduta, sintomas psicossomáticos, depressão, risco de suicídio e uso de álcool, tabaco e drogas ilícitas ${ }^{4,11,12}$.

Enquanto os comportamentos de bullying tendem a ser rejeitados pela maioria da população, embora aconteçam com muita frequência, o consumo de álcool é praticado e, até certo nível, aceito socialmente. Estudos apontam que, embora o uso de substâncias psicoativas enfrente certas limitações e constrangimentos, este ainda é um hábito largamente praticado, especialmente a partir da adolescência ${ }^{1,3}$. O álcool, substância mais consumida nessa etapa do desenvolvimento, tem seu consumo na vida referido por $60 \%$ a $70 \%$ dos adolescentes brasileiros ${ }^{1,3}$. Desconsiderando-se tabaco e álcool, 22,8\% dos 7.939 adoles- centes entrevistados, no II Levantamento domiciliar sobre uso de drogas psicotrópicas no Brasil - 2005, já fizeram uso de drogas na vida ${ }^{13}$. Neste mesmo levantamento, a estimativa de adolescentes dependentes de álcool foi de $12,3 \%$ e, de tabaco, 10,1\%. Além disso, a adolescência foi apontada como a etapa do desenvolvimento em que se dá o início do uso de substâncias psicoativas: entre 12 e 17 anos já se percebe o uso das mais variadas substâncias e, entre o sexo masculino, um terço declarou já ter se submetido a tratamento para dependência de drogas. Nesta faixa etária, o álcool já foi consumido por 54,3\% dos adolescentes, sendo $7 \%$ considerados dependentes. Ainda, 15,2\% já experimentaram cigarro, sendo 2,9\% dependentes de tabaco. Por fim, a maconha já foi utilizada por $4,1 \%$ dos adolescentes ${ }^{13}$.

Assim como o bullying, o uso de substâncias psicoativas pode prejudicar o desenvolvimento físico, emocional e social dos indivíduos. Estudos associam este hábito a envolvimento em acidentes e brigas, problemas no desempenho acadêmico e profissional, prática de relações sexuais com maior número de parceiros e de risco (sem uso de preservativos), depressão, ansiedade, baixa autoestima, distúrbios psiquiátricos menores e transtornos de conduta ${ }^{11,14,15}$.

Percebe-se que o envolvimento em situações de bullying e o uso de substâncias psicoativas constituem-se em fatores de risco na adolescência e que vários problemas de saúde são comuns como consequência do envolvimento com esses fenômenos. Além disso, ambos apresentam grande prevalência nessa etapa da vida e, portanto, estão presentes de forma significativa no ambiente escolar, prejudicando o desempenho acadêmico dos envolvidos, além de aparecem frequentemente relacionados a um dos grandes problemas de saúde pública: a violência de um modo geral ${ }^{2,4,8,12,13}$. São, ainda, fenômenos que influenciam e são influenciados pelos grupos de iguais, uma vez que tanto o bullying como o uso de substâncias psicoativas costumam ser situações que o jovem vivencia junto com amigos, seja pela simples oferta ou pela função integradora que o envolvimento nesses comportamentos pode representar ${ }^{16,17}$.

Uma compreensão mais profunda destes fenômenos e da relação entre eles, necessária na promoção de cuidados dirigidos à prevenção ou ao manejo de situações típicas, depende ainda de uma sistematização das evidências disponíveis que reflitam em que medida bullying e uso de substâncias estão associados e se esta relação se modifica segundo os diferentes papéis sociais 
identificados entre os envolvidos em bullying (vítima, vítima-agressor ou agressor). Para responder a isso, foi realizada uma revisão sistemática da literatura sobre bullying e uso de substâncias.

\section{Método}

O presente estudo, baseado no método Prefered Reporting Items for Systematic Reviews and $\mathrm{Me}$ ta-Analyses - PRISMA ${ }^{18,19}$, foi conduzido por quatro pesquisadores, de forma independente e cega. A busca de artigos foi realizada em duas etapas: em janeiro de 2014 para publicações de janeiro de 2009 a dezembro de 2013 e, em março de 2015, para publicações de janeiro a dezembro de 2014. Foram pesquisadas as seguintes bases de dados eletrônicas: Biblioteca Virtual em Saúde (BVS), American Psychological Association (APA), Education Resources Information Center (ERIC), Index Psi Periódicos (IndexPsi), EBSCO Information Services (EBSCO), Web of Science e Oxford University Press. Os descritores utilizados para a busca de artigos foram definidos a partir dos termos indexados no vocabulário estruturado DeCS (Descritores em Ciências da Saúde) e no vocabulário de indexação de artigos da PubMed, o Medical Subject Headings (MeSH terms), estabelecendo-se a seguinte sintaxe: bullying AND drugs OR drug abuse OR substance OR dependency OR alcohol OR cannabis OR crack OR cocaine OR tobacco.

Para a inclusão dos artigos localizados nessa busca, foram adotados os seguintes critérios: 1) tratar-se de artigo empírico, 2) publicado entre janeiro de 2009 e dezembro de 2014, 3) realizado com população adolescente, 4) que relacionasse bullying e uso de substâncias psicoativas e 5) publicado em idiomas inglês, espanhol ou português. Foram excluídos: 1) os artigos repetidos, 2) aqueles que enfocavam apenas um dos temas (somente bullying ou somente uso de drogas), 3) os que mencionaram os dois temas sem examinar a relação entre eles, 4) estudos que trataram apenas de cyberbullying, 5) artigos que não estudaram nenhum dos temas e 6) estudos cuja qualidade metodológica foi considerada ruim.

Após a leitura dos títulos e resumos das produções encontradas em cada base, foram aplicados os critérios de exclusão pelos juízes, com consenso de uma terceira juíza. Quando essa leitura não se mostrou suficiente para a definição sobre a adequação ou não do artigo aos critérios de inclusão definidos, os mesmos foram mantidos para a etapa seguinte do estudo, que envol- veu a leitura dos artigos na íntegra. Durante esta etapa, outro critério de exclusão foi estabelecido: estudos que abordaram o bullying sem explicitar o conceito utilizado. Assim, foram considerados artigos que abordaram o bullying aqueles que explicitaram alguma definição do fenômeno para o estudo das variáveis relacionadas, correspondendo a algum tipo de violência interpessoal, que ocorre repetidamente, com a intenção de ofender (agressão verbal), machucar (agressão física) ou humilhar (agressão relacional) alguém de idade igual ou semelhante, sem motivação evidente, causando dor, angústia ou humilhação ${ }^{4,7-9}$. Artigos que empregaram a expressão bullying sem qualquer detalhamento do conceito a quem respondia o instrumento e sem a investigação de detalhes que caracterizassem o conceito assumido aqui, foram excluídos, por não haver garantias de que seus resultados poderiam ser comparados aos resultados de artigos que apresentaram adequada caracterização do fenômeno. Em relação à faixa etária, nos casos em que os autores dos artigos encontrados não apresentaram este dado, considerou-se que o estudo de fato referia-se a uma população adolescente quando a etapa de escolarização correspondia ao esperado para esta fase do desenvolvimento. Por fim, como uso de substâncias psicoativas foi considerada a investigação de qualquer tipo de uso de drogas lícitas e ilícitas. Ainda, a qualidade do artigo foi avaliada durante a sua leitura na íntegra, verificando-se a apresentação e adequação dos procedimentos metodológicos utilizados e os riscos de ocorrência de vieses de seleção, de delineamento, de validade interna, além de possíveis conflitos de interesse dos autores e o relato do controle de vieses em cada estudo analisado ${ }^{20}$. Não foram incluídos na revisão estudos com vieses detectados pela equipe de pesquisa e percebidos como determinantes de algum prejuízo para as estimativas apresentadas no artigo.

Concluída a leitura integral dos textos, o conteúdo dos artigos foi organizado e categorizado. Foram registradas as seguintes informações: identificação do artigo, delineamento do estudo, características da amostra e resultados obtidos sobre a relação entre bullying e uso de substâncias psicoativas.

\section{Resultados}

A estratégia de busca inicial identificou 585 registros. Aplicados os critérios de inclusão, 389 registros foram selecionados. Destes, 161 eram repe- 
tidos dentro das bases, gerando um total de 228 registros, cujos títulos e resumos foram analisados. Aplicados os demais critérios de exclusão, 83 registros foram excluídos por abordarem apenas um dos temas, 82 por abordarem os dois temas, sem estudar a relação entre eles, 11 apresentaram dados exclusivos sobre cyberbullying, 04 não estudavam nenhum dos temas aqui abordados, 04 não explicitaram o conceito utilizado para o estudo do bullying e 04 foram considerados de qualidade metodológica ruim. Restaram, assim, 40 artigos, os quais foram selecionados para efetiva análise dos dados. A Figura 1 apresenta o detalhamento deste processo.
$\mathrm{Na}$ análise dos artigos, alguns aspectos destacaram-se: diferentes delineamentos de estudos do tema, processos amostrais envolvendo predominantemente escolares e não a população de adolescentes como um todo, e resultados controversos obtidos sobre a relação entre bullying e uso de substâncias psicoativas, especialmente quanto à vitimização por bullying.

Com relação ao delineamento, a maioria dos estudos é quantitativo, uma vez que apenas um dos 40 artigos apresentou delineamento qualitativo. Entre os estudos quantitativos, $24(61 \%)$ são de delineamento transversal, 10 (26\%) são estudos longitudinais, e 5 (13\%) apresentaram

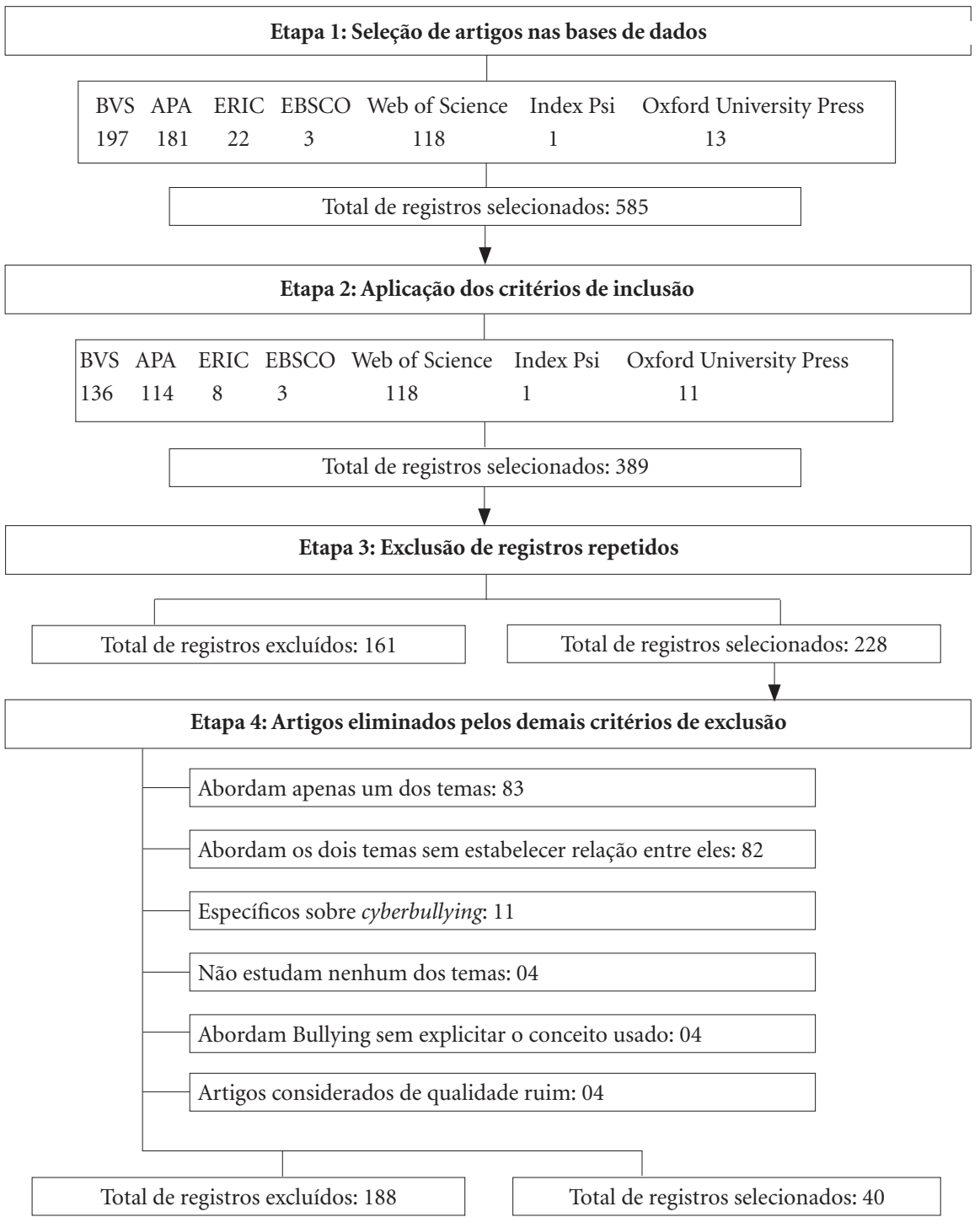

Figura 1. Fluxograma das etapas de busca e seleção dos artigos analisados. 
outros tipos de delineamentos. Quanto às amostras, nota-se que a escola aparece como local onde bullying e uso de substâncias psicoativas entre adolescentes são preferencialmente estudados $(87,5 \% ; n=35)$. A escola, principalmente em países e em anos escolares nos quais há limitada ocorrência de abandono escolar, pode permitir uma boa aproximação da população adolescente do território onde ela se insere. Contudo, não se pode assegurar essa relação. Portanto, é mais adequado explorar as evidências destes estudos falando da população de escolares. Depois da escola, instituições hospitalares $(5 \% ; n=2)$ e outros locais $(5 \% ; n=2)$ foram sede dos estudos. Apenas uma ivestigação $(2,5 \%)$ era um inquérito de base domiciliar. A maioria dos estudos apresentou amostras mistas, compostas de adolescentes de ambos os sexos (95\%; $n=38)$, havendo dois estudos realizados apenas com meninos (5\%).

Entre os estudos de delineamento quantitativo transversal que analisaram o papel de vítima, nota-se que mais da metade $(65 \% ; n=13)$ evidenciou aumento da ocorrência de uso de substâncias associado à vitimização por bullying. O Quadro 1 apresenta as principais evidências dos estudos com essas características. Há dados que associam a vitimização com uso de ál$\mathrm{cool}^{21-23}$, tabaco ${ }^{22,24-26}$ e maconha no mês ${ }^{24}$, álcool e outras drogas no mês ${ }^{10,12,26,27}$ e no ano ${ }^{28}$, tabaco e álcool na vida ${ }^{29}$, além de uso pesado de álcool no ano ${ }^{22,30}$. O artigo de Espelage et al. ${ }^{28}$ explorou a condição de polivítimas, mostrando que esses foram os que mais consumiram álcool e outras drogas.

Por sua vez, o Quadro 2 apresenta dados dos estudos transversais que não evidenciaram aumento da ocorrência de uso de substâncias associado à vitimização ou não estudaram vitimização. Entre os 12 artigos referidos neste quadro, sete (35\%) não encontraram aumento da ocorrência de uso de substâncias associado à vitimização. Neste sentido, Garcia-Continente et al. ${ }^{31}$ identificaram, entre os meninos vitimizados, uma menor chance de uso na vida de maconha, enquanto as meninas vítimas apresentaram menor chance de uso de risco de álcool nos últimos 6 meses. Em outro estudo, Garcia-Continente et al. ${ }^{32}$ encontraram a menor chance de uso na vida de maconha entre as vítimas estudadas, independentemente do sexo. Outros estudos identificaram, ainda, associação negativa entre vitimização por bullying e uso pesado de álcool ${ }^{33}$ e uso pesado de álcool e outras substâncias no ano ${ }^{34}$. Analisando-se conjuntamente os Quadros 1 e 2, nota-se estudos que apontam para a ausência de associa- ção entre vitimização e uso de álcool no mês ${ }^{24,35}$, tabaco na semana e outras drogas no $a^{33}$ e álcool e outras substâncias ${ }^{36}$. Embora Vieno et al..$^{29}$ tenham encontrado associação entre vitimização e uso de tabaco e álcool na vida, esta associação não se manteve para vitimização em bullying verbal e tabagismo, assim como para vitimização por racismo e uso de álcool.

Embora a relação entre uso de substâncias e vitimização por bullying mostre-se controversa, o mesmo não ocorreu em relação ao papel de agressor. Tanto no Quadro 1 como no Quadro 2, é possível perceber a associação entre ser agressor e fazer uso de substâncias psicoativas, apontada por todos os estudos de delineamento transversal que estudaram este papel social do bullying. Entre os estudos que analisaram também os outros papéis sociais do bullying, os agressores apareceram como sendo os que mais fazem uso de substâncias, seguidos por agressores-vítimas e, por fim, pelas vítimas. Assim como aconteceu em relação aos jovens polivítimas ${ }^{28}$, agressores envolvidos em todos os tipos de bullying referiram mais uso de substâncias quando comparados a envolvidos em apenas um ou dois tipos de bullying ${ }^{37}$.

Apesar de algumas discrepâncias entre os resultados, os estudos de delineamento quantitativo longitudinal (Quadro 3) também evidenciaram associação do bullying no papel de agressor com uso de cigarros ${ }^{38}$, álcool ${ }^{39}$ ou outras drogas ${ }^{38}$. Nota-se, ainda, o estudo de Espelage et al..$^{40}$, que aponta para a perpetração de bullying como fator de mediação entre violência familiar e uso de álcool, cigarro e solventes entre os meninos. No entanto, foi encontrado um estudo mostrando associação com o uso de álcool, cigarro e outras drogas no último ano apenas para bullying verbal e relacional ${ }^{41}$, e outro indicando que praticar o bullying não prediz o uso de drogas na adolescência, mas prediz na idade adulta ${ }^{42}$. Apenas no estudo de Weiss et al. ${ }^{43}$ não foi encontrada associação entre perpetração do bullying e tabagismo.

Já em relação à vitimização por bullying, há estudos longitudinais (Quadro 3) indicando ausência de associação com uso de álcool e maconha ${ }^{39,44}$ e álcool e outras drogas ${ }^{45}$, enquanto outros apontam para a existência de associação entre vitimização por bullying e uso de cigarros $^{38,44,46}$, álcool $^{46,47}$, maconha ${ }^{46}$ e outras substâncias ${ }^{46}$. Ressalta-se que a vitimização no $9^{\circ}$ ano escolar mediou a relação entre coesão familiar e uso de tabaco $^{44}$, e que vitimização no tempo 1 (T1) do estudo longitudinal foi preditor de uso de álcool para coping (por exemplo, para esquecer tristezas, melhorar o humor ou lidar com sentimentos de 
Quadro 1. Estudos Transversais que evidenciaram aumento da ocorrência de uso de substâncias associado à vitimização por bullying.

\begin{tabular}{|c|c|c|}
\hline Autor/ano & Amostra & Evidências \\
\hline $\begin{array}{l}\text { Bradshaw et } \\
\text { al. }(2013)^{24}\end{array}$ & $\begin{array}{l}\mathrm{N}=16.302 \text { Escolares } \\
\text { de Maryland (EUA) } \\
\text { afroamericanos e } \\
\text { caucasianos. } \\
\text { Idade: } 12 \text { a } 21 \text { anos. }\end{array}$ & $\begin{array}{l}\text { Regressão linear ajustada com modelo hierarquizado: Nível I: } \\
\text { Idade, sexo, raça; Nível II: nível de ensino; Nível III: urbanicidade } \\
\text { da escola, ambiente, número de matrículas, percentual de minorias } \\
\text { e percentual de suspensões na escola. Exposição: Papéis sociais no } \\
\text { bullying. Desfecho: Consumo de substâncias nos últimos } 30 \text { dias } \\
\text { - Vítimas: Álcool (OR = 1,10; IC95\%:0,989-1,217); Tabaco (OR = } \\
\text { 1,64; IC95\%:1,452-1,860); Maconha (OR =1,30; IC95\%: 1,145- } \\
\text { 1,485); Agressores: Álcool (OR = 3,08; IC95\%:2,737-3,457); Tabaco } \\
(\mathrm{OR}=2,66 ; \text { IC95\%:2,229-3,167); Maconha (OR = 2,77; IC95\%: } \\
\text { 2,439-3,155); Agressores-Vítimas: Álcool (OR =3,20; IC95\%:2,651- } \\
\text { 3,874); Tabaco (OR =4,72; IC95\%:3,915-5,679); Maconha (OR = } \\
\text { 3,71; IC95\%: 3,101-4,438). }\end{array}$ \\
\hline $\begin{array}{l}\text { Espelage et al. } \\
(2012)^{28}\end{array}$ & $\begin{array}{l}\mathrm{N}=992 \text { Escolares do } \\
\text { Centro-Oeste (EUA). } \\
\text { Idade: } 10 \text { a } 15 \text { anos. }\end{array}$ & $\begin{array}{l}\text { Análise por cluster para definir variáveis de exposição (não vítimas } \\
\text { de bullying-NV e vítimas em bullying: relacional-VR, homofóbico- } \\
\text { VH e polivítimas-PV). ANOVA para escore de uso de AOD no } \\
\text { último ano segundo clusters de exposição: } F=10,7(\mathrm{p}<0,01), \mathrm{com} \\
\text { todas as formas de vitimização com médias maiores que } N V(\mathrm{~m}= \\
1,12 ; \mathrm{dp}=0,33) . P V \text { foram os que mais consumiram AOD }(\mathrm{m}= \\
1,33 ; \mathrm{dp}=0,53) .\end{array}$ \\
\hline $\begin{array}{l}\text { Luk et al. } \\
(2012)^{48}\end{array}$ & $\begin{array}{l}\mathrm{N}=7.508 \text { Escolares } \\
\text { norte-americanos. Idade } \\
\text { média: } 14,2 \text { anos. }\end{array}$ & $\begin{array}{l}\text { Análise de classes latentes (LCA) para uso de substâncias (cigarro, } \\
\text { álcool e maconha nos últimos } 30 \text { dias) e vitimização em bullying. } \\
\text { Variáveis independentes: idade, sexo, etnia, tempo com amigos, } \\
\text { conhecimento dos pais sobre os filhos. A coocorrência entre bullying } \\
\text { e uso de substâncias foi de } 5.4 \% \text {, com: maior chance de ocorrer para: } \\
\text { maior idade: [OR = } 1,38(\mathrm{IC} 95 \%: 1,27-1,50)] \text {, menor conhecimento } \\
\text { materno: }[\mathrm{OR}=5,38(\mathrm{IC} 95 \%: 3,73-7,74)] \text {, menor conhecimento } \\
\text { paterno: [OR = 2,05 (IC95\%:1,47-2,88)], mais tempo com amigos: } \\
\text { [OR = 3,00 (IC95\%:2,19-4,43)]; e menor chance de ocorrer para } \\
\text { estudantes do sexo feminino [OR =0,68 (IC95\%: } 0,48-0,95)] \text {. }\end{array}$ \\
\hline $\begin{array}{l}\text { McGee et al. } \\
(2011)^{21}\end{array}$ & $\begin{array}{l}\mathrm{N}=6.748 \text { Escolares de } \\
\text { San Diego (EUA). } \\
\text { Idade: } 13 \text { a } 18 \text { anos. }\end{array}$ & $\begin{array}{l}\text { Análise de correlação entre escore de vitimização por pares (bullying) } \\
\text { nos últimos } 12 \text { meses e uso de álcool no último mês correlação } \\
\text { positiva entre sofrer bullying e uso de álcool: }=0,25(\mathrm{p}<0,001) \text {. }\end{array}$ \\
\hline $\begin{array}{l}\text { Pan e Spittal. } \\
(2013)^{22}\end{array}$ & $\begin{array}{l}\mathrm{N}=8.182 \text { Escolares } \\
\text { chineses, do } 7^{\circ} \text { ao } 10^{\circ} \\
\text { ano. }\end{array}$ & $\begin{array}{l}\text { Regressão linear por modelo misto generalizado para } \\
\text { comportamentos em saúde, comparando vítimas de bullying } \\
\text { religioso, racial e outros que não estes com não envolvidos, ajustada } \\
\text { para idade, sexo e nível socioeconômico. Vítimas de bullying não } \\
\text { religioso nem racial: Tabagismo: OR = 1,40 (IC95\%:1,13-1,73) e } \\
\text { álcool moderado e pesado: OR = 1,57 (IC 95\%: 1,06-2,32). }\end{array}$ \\
\hline $\begin{array}{l}\text { Pierobon et } \\
\text { al. }(2013)^{23}\end{array}$ & $\begin{array}{l}N=1.328 \text { Escolares } \\
\text { argentinos. } \\
\text { Idade: } 13 \text { a } 15 \text { anos. }\end{array}$ & $\begin{array}{l}\text { Regressão logística, ajustada por idade, estratificada por sexo. } \\
\text { Exposição: ter sido vítima de bullying no mês. Desfecho: uso de } \\
\text { álcool no mês. Meninos: OR =1,51 (IC95\%: } 1,01-2,26) \text {. Meninas: } \\
\text { OR }=1,90 \text { (IC95\%: } 1,32-2,75)\end{array}$ \\
\hline
\end{tabular}

depressão ou ansiedade) e também de problemas relacionados ao uso de álcool em $\mathrm{T} 22^{47}$.

Por fim, o Quadro 4 apresenta os resultados de estudos com outros tipos de delineamento. Aqui foram reunidos os dados do estudo qualitativo e de estudos que aplicaram Modelo de Equações Estruturais ou Análise de Mediação, usualmente aplicadas a estudos longitudinais, sobre dados de estudos transversais. Observa-se associação entre vitimização por bullying e uso de substâncias apenas para os meninos após o controle para presença de sintomas depressivos ${ }^{11}$ e apenas a vitimização por bullying físico como preditora de uso de álcool e outras drogas ${ }^{49}$. Há, 
Quadro 1. continuação

\begin{tabular}{|c|c|c|}
\hline Autor/ano & Amostra & Evidências \\
\hline $\begin{array}{l}\text { Radliff et al. } \\
(2012)^{12}\end{array}$ & $\begin{array}{l}\mathrm{N}=74.247 \text { Escolares de } \\
\text { Franklin (Ohio/ EUA), } \\
\text { do } 6^{\circ} \text { ao } 12^{\circ} \text { anos. }\end{array}$ & $\begin{array}{l}\text { Chi-quadrado com Análise de Resíduos Padronizados Ajustados } \\
\text { (ASR), estratificada por nível de ensino. Desfechos: uso de tabaco, } \\
\text { álcool e maconha nos últimos } 30 \text { dias. Exposição: Papéis sociais no } \\
\text { bullying no ensino fundamental: Agressores têm maiores prevalências } \\
\text { dos desfechos, seguidos por agressores-vítimas. Não envolvidos têm } \\
\text { as menores prevalências, inclusive em relação às vítimas. No ensino } \\
\text { médio, agressores-vítimas apresentam maior uso de tabaco e álcool } \\
\text { que agressores. Outros dados acompanham ensino fundamental. }\end{array}$ \\
\hline $\begin{array}{l}\text { Ringwalt e } \\
\text { Shamblen. } \\
(2012)^{27}\end{array}$ & $\begin{array}{l}\mathrm{N}=53.750 \text { Escolares de } \\
\text { Oregon (EUA), do } 6^{\circ}, 8^{\circ} \\
\text { e } 11^{\circ} \text { ano. }\end{array}$ & $\begin{array}{l}\text { Correlação de Pearson para escores de uso e uso pesado de álcool, } \\
\text { maconha, inalantes, outras drogas (cocaína, ecstasy, heroína, } \\
\text { alucinógenos, anfetaminas e medicamentos) e qualquer droga no } \\
\text { mês entre vítimas de bullying, segundo o motivo percebido para a } \\
\text { vitimização, no mês (amizades; características físicas; orientação } \\
\text { sexual; etnia; outras razões), ajustada para sexo, idade e etnia: } \\
\text { Correlações baixas, mas significativas ( }<0,05 \text { ), entre uso de todas } \\
\text { as substâncias e todos os motivos em estudo (r variando de } 0,07 \text { a } \\
0,15) \text {. }\end{array}$ \\
\hline $\begin{array}{l}\text { Silva et al. } \\
(2012)^{26}\end{array}$ & $\begin{array}{l}\mathrm{N}=1.145 \text { Residentes em } \\
\text { Pelotas / Brasil. Idade: } 11 \\
\text { a } 15 \text { anos. }\end{array}$ & $\begin{array}{l}\text { Chi-quadrado e ANOVA para escores de vitimização por bullying } \\
\text { nas últimas duas semanas. Variáveis independentes: uso de álcool no } \\
\text { mês, embriaguez no mês, tabagismo no mês, uso de outras drogas } \\
\text { no mês, sexo, idade, faltas às aulas, fracasso escolar, atividade sexual, } \\
\text { porte de armas, envolvimento em acidentes, envolvimento em brigas. } \\
\text { Consumir álcool, embriagar-se e fazer uso de tabaco ou drogas } \\
\text { ilícitas no último mês aumentou significativamente a média do } \\
\text { escore de vitimização por bullying estudado (p < } 0,001 \text { para todos os } \\
\text { comportamentos relacionados a uso de substâncias). }\end{array}$ \\
\hline $\begin{array}{l}\text { Tee e Kaur. } \\
(2014)^{25}\end{array}$ & $\begin{array}{l}\mathrm{N}=25.507 \text { Escolares da } \\
\text { Malásia. } \\
\text { Idade: } 12 \text { a } 17 \text { anos. }\end{array}$ & $\begin{array}{l}\text { Regressão logística multivariável ajustada. Exposição: Vitimização } \\
\text { por bullying em } 12 \text { meses. Desfecho: Tabagismo } \\
\text { Tabagismo entre vítimas de bullying, comparado a não vítimas: OR = } \\
\text { 1,41 (IC95\%: 1,00 - 1,98). }\end{array}$ \\
\hline $\begin{array}{l}\text { Vieno et al. } \\
(2011)^{29}\end{array}$ & $\begin{array}{l}\mathrm{N}=2.566 \text { Escolares } \\
\text { italianos. } \\
\text { Idade: } 13 \text { a } 15 \text { anos. }\end{array}$ & $\begin{array}{l}\text { Regressão logística ajustada para sexo, ano escolar e nível de } \\
\text { educação dos pais. Exposição: papéis sociais no bullying (vítima, } \\
\text { agressor e vítima/agressor) em diferentes tipos de bullying (físico, } \\
\text { verbal, relacional, sexual, cyber e racial). Desfecho: tabagismo e uso } \\
\text { de álcool no presente. Associação_entre o envolvimento em bullying } \\
\text { nos diferentes papéis e uso de cigarro e álcool na vida, variando de } \\
\text { OR = 1,39 (IC95\%: } 1,00 \text { - 2,01) para tabagismo e vitimização em } \\
\text { bullying relacional, até OR = 5,00 (IC95\%: } 2,71 \text { - 9,25) para uso } \\
\text { de álcool e agressão em bullying por racismo. Não significativo para } \\
\text { vitimização em bullying verbal e tabagismo [OR = 1,16 (IC95\%: } \\
0,74-1,81 \text { )] e uso de álcool [OR =0,84 (IC95\%: 0,51 - 1,39)] e } \\
\text { vitimização em bullying por racismo e uso de álcool [OR = 0,80 } \\
\text { (IC95\%: } 0,18-3,51 \text { )]. }\end{array}$ \\
\hline $\begin{array}{l}\text { Yen et al. } \\
(2014)^{30}\end{array}$ & $\begin{array}{l}\mathrm{N}=6.406 \text { Escolares da } \\
\text { região sul de Taiwan. } \\
\text { Idade: } 11 \text { a } 19 \text { anos. }\end{array}$ & $\begin{array}{l}\text { Regressão logística ajustada para sexo e idade, estratificada para tipo } \\
\text { de bullying: passivo - BP (exclusão, apelidos e difamação) ou ativo } \\
\text { - BA (agressão física, exploração e roubo) no ano. Exposição: papel } \\
\text { no bullying (não envolvidos, vítima ou agressor). Desfecho: abuso de } \\
\text { álcool. } \\
\text { Em BP: OR para abuso de álcool, comparado a não envolvidos: } \\
\text { Vítimas: OR = 1,738 (IC95\%: 1,384-2,183) e Agressores: OR =3,029 } \\
\text { (IC95\%: 2,372-3,867). Em BA: Vítimas: OR =1,599 (IC95\%: } 1,354 \text { - } \\
\text { 1,889) e Agressores: OR =1,753 (IC95\%: } 1,477-2,080 \text { ). }\end{array}$ \\
\hline
\end{tabular}

Legenda: AOD - Álcool e Outras Drogas; ns - Não Significativa. 
Quadro 2. Estudos Transversais que não evidenciaram aumento da ocorrência de uso de substâncias associado à vitimização por bullying ou não estudaram vitimização.

\begin{tabular}{|c|c|c|}
\hline Autor/ano & Amostra & Evidências \\
\hline $\begin{array}{l}\text { Cerezo e } \\
\text { Méndez. } \\
(2012)^{50}\end{array}$ & $\begin{array}{l}\mathrm{N}=1.239 \text { Escolares de } \\
\text { Murcia (Espanha).. } \\
\text { Idade: } 11 \text { a } 18 \text { anos }\end{array}$ & $\begin{array}{l}\text { Chi-quadrado para taxa de consumo de AOD no ano }(\mathrm{p}<0,001) \text { e } \\
\text { taxa de policonsumo no ano }(2 \mathrm{ou}+\text { substâncias em até duas horas }) \\
(\mathrm{p}<0,001) \text { segundo envolvimento em bullying; ANOVA para taxa } \\
\text { de consumo } \mathrm{F}=12,026(\mathrm{p}<0,001) \text { e para taxa de policonsumo } \mathrm{F}= \\
14,782(\mathrm{p}<0,001) \text { e comparação entre papéis para taxa de consumo: } \\
\text { Neutro/agressor }=-0,281(\mathrm{p}<0,001) ; \text { Agressor } / \text { Vitima }=0,428(\mathrm{p}< \\
0,001) ; \text { itmia/vitima-agressor }=-0,805(\mathrm{p}=0,005) .\end{array}$ \\
\hline $\begin{array}{l}\text { Fossati et al. } \\
(2012)^{34}\end{array}$ & $\begin{array}{l}\mathrm{N}=763 \text { Escolares de } \\
\text { Milão (Itália). } \\
\text { Idade Média: } 16,7 \text { anos. }\end{array}$ & $\begin{array}{l}\text { Correlação de Spearman para escores de uso pesado de álcool e uso } \\
\text { de outras substâncias }(\text { OS) no ano qualquer dia da semana (DS) } \\
\text { ou finais de semana (FS), comparando agressão e vitimização em } \\
\text { bullying, ajustada para idade e sexo: agressor e álcool FS }(\rho=0,24 ; \mathrm{p} \\
<0,05) \text {, álcool DS }(\rho=0,22 ; \mathrm{p}<0,05) \text {, OS FS }(\rho=0,28 ; \mathrm{p}<0,05) \text { e } \\
\text { OS DS ( } \rho=0,26 ; \mathrm{p}<0,05) ; \text { vítimas e álcool FS }(\rho=-0,13 ; \mathrm{p}<0,05) \text { e } \\
\text { OS FS }(\rho=-0,13 ; \mathrm{p}<0,05) \text {. Demais resultados: ns. }\end{array}$ \\
\hline $\begin{array}{l}\text { Garcia- } \\
\text { Continente et } \\
\text { al. }(2010)^{31}\end{array}$ & $\begin{array}{l}\mathrm{N}=2.727 \text { Escolares de } \\
\text { Barcelona. } \\
\text { Idade média: } 15,3 \text { anos. }\end{array}$ & $\begin{array}{l}\text { Regressão logística multivariável, estratificada por sexo, para } \\
\text { vitimização em bullying segundo uso recente de tabaco, uso na vida } \\
\text { de maconha, uso de risco de álcool nos últimos } 6 \text { meses, idade, tipo } \\
\text { de escola, nível de ensino, nível socioeconomico, coabitação com } \\
\text { pai e mãe, ócio noturno, atividades extraclasse, conduta antissocial, } \\
\text { estado de animo negativo, conduta violenta. } \\
\text { Meninos: uso na vida de maconha: OR = 0,41 (IC95\%: 0,26-0,65); } \\
\text { Meninas: uso de risco de álcool: OR = 0,50 (IC95\%: 0,32-0,78). }\end{array}$ \\
\hline $\begin{array}{l}\text { Garcia- } \\
\text { Continente et } \\
\text { al. }(2013)^{32}\end{array}$ & $\begin{array}{l}\mathrm{N}=3.089 \text { Escolares de } \\
\text { Barcelona. } \\
\text { Idade: } 13 \text { a } 18 \text { anos. }\end{array}$ & $\begin{array}{l}\text { Regressão de Poisson Robusta para uso na vida de AOD segundo } \\
\text { papéis sociais no bullying, comparados a nenhum envolvimento, } \\
\text { ajustada para idade, sexo, série escolar, escore na Family Affluence } \\
\text { Scale, estado de animo, conduta antissocial, IMC. } \\
\text { Uso na vida de maconha: por vítimas [RP = 0,50 (IC95\%: 0,32- } \\
0,81) \text { ] e por agressores [RP =1,38 (IC95\%: } 1,02-1,87)] \\
\text { Uso na vida de álcool por agressores [RP = 1,54 (IC95\%: 1,12-2,13)]. } \\
\text { Demais resultados: ns. }\end{array}$ \\
\hline $\begin{array}{l}\text { Gower e } \\
\text { Borowsky. } \\
(2013)^{51}\end{array}$ & $\begin{array}{l}\mathrm{N}=128.681 \text { Escolares } \\
\text { de Minnesota (EUA), do } \\
6^{\circ}, 9^{\circ} \text { e } 12^{\circ} \text { anos. }\end{array}$ & $\begin{array}{l}\text { Regressão logística estratificada por nível de ensino, para uso } \\
\text { de álcool, tabaco, maconha e outras drogas nos últimos } 30 \text { dias, } \\
\text { segundo frenquencia no papel de agressor no bullying, ajustada } \\
\text { para sexo, sofrimento psíquico, automutilação, envolvimento em } \\
\text { brigas, uso de outras substâncias. Agressores comparados a não } \\
\text { envolvidos: maconha [OR }=1,53 \text { (IC95\%:1,44-1,63)] para alunos do } \\
12^{\circ} \text { ano até álcool [OR }=2,84 \text { (IC95\%: } 2,50-3,23 \text { )] para alunos do } \\
6^{\circ} \text { ano (associações com menor magnitude sempre para séries mais } \\
\text { avançadas). }\end{array}$ \\
\hline $\begin{array}{l}\text { King et al. } \\
(2013)^{52}\end{array}$ & $\begin{array}{l}\mathrm{N}=433 \text { Hospitalizados. } \\
\text { Idade: } 13 \text { a } 17 \text { anos. }\end{array}$ & $\begin{array}{l}\text { Teste T de Student para escore na PESQ (abuso de álcool e outras } \\
\text { substâncias) na hospitalização por risco de suicídio, comparando } \\
\text { agressores e não agressores. Agressores: } \mathrm{m}=33,33(\mathrm{dp}=11,9) \text { e Não } \\
\text { agressores: } \mathrm{m}=27,54(\mathrm{dp}=11,5) \mathrm{p}<0,001 \text {. }\end{array}$ \\
\hline
\end{tabular}

também, um estudo indicando ausência de associação entre vitimização por bullying e o uso de cigarros $^{53}$ e outro indicando que ser vítima de bullying contribui para não haver consumo de álcool, enquanto o envolvimento com a perpetração do bullying contribui para o consumo ${ }^{54}$. Além disso, a inclusão dos motivos para beber no modelo de equações estruturais utilizado pelos pesquisadores evidencia uma relação entre o efeito do envolvimento em algum dos papeis sociais de bullying e o uso de álcool ${ }^{54}$. Por outro lado, verifica-se, entre os estudos apresentados no Quadro 4, uma maior chance de agressores fazerem uso diário de tabaco ${ }^{53}$ e o consumo pro- 
Quadro 2. continuação

\begin{tabular}{|c|c|c|}
\hline Autor/ano & Amostra & Evidências \\
\hline $\begin{array}{l}\text { Luukkonen } \\
\text { et al. } \\
(2010)^{36}\end{array}$ & $\begin{array}{l}\mathrm{N}=508 \text { Hospitalizados } \\
\text { em hospital psiquiátrico. } \\
\text { Idade: } 12 \text { a } 17 \text { anos. }\end{array}$ & $\begin{array}{l}\text { Regressão logística para uso de substâncias no presente (tabaco, } \\
\text { álcool, maconha e outras drogas), segundo papéis sociais no } \\
\text { bullying, comparados a nenhum envolvimento neste, estratificada } \\
\text { por sexo e ajustada para idade, morbidade psíquica, tipo de família, } \\
\text { ocupação de pai e mãe, uso de substâncias e morbidade psíquica } \\
\text { entre familiares: Agressão e uso de tabaco (meninos): OR = 3,02 } \\
\text { (IC95\%: 1,08-8,41), tabaco (meninas): OR = 14,83 (IC95\%: } 1,92- \\
\text { 114,83), álcool (meninos): OR = 2,34 (IC95\%: 1,05-5,22), maconha } \\
\text { (meninas): OR = 8,28 (IC95\%: 2,42-28,32), outras drogas (meninas): } \\
\text { OR =6,43 (IC95\%: 1,34-31,01). Demais resultados: ns. }\end{array}$ \\
\hline $\begin{array}{l}\text { McMahon et } \\
\text { al. }(2010)^{33}\end{array}$ & $\begin{array}{l}\mathrm{N}=1.870 \text { Escolares } \\
\text { do sexo masculino da } \\
\text { Irlanda. }\end{array}$ & $\begin{array}{l}\text { Regressão logística multivariável, ajustada por idade. Exposições: } \\
\text { Consumo pesado de álcool (quatro ou mais episódios de } \\
\text { embriaguez) no ano, tabagismo e uso de outras drogas no ano. } \\
\text { Desfecho: vitimização por bullying. } \\
\text { Uso pesado de álcool, comparado a quem não referiu: OR =0,72 } \\
\text { (IC95\%: 0,56-0,93). Demais resultados: ns. }\end{array}$ \\
\hline $\begin{array}{l}\text { Peleg-Oren et } \\
\text { al. }(2010)^{35}\end{array}$ & $\begin{array}{l}\mathrm{N}=44.532 \text { Escolares } \\
\text { do } 6^{\circ} \text { ao } 8^{\circ} \text { anos, do } \\
\text { FYSAS/2008 (Flórida/ } \\
\text { EUA). }\end{array}$ & $\begin{array}{l}\text { Regressão logística multivariável, ajustada para sexo, etnia e série } \\
\text { escolar, estratificada para os papéis sociais. Exposição: Uso de álcool } \\
\text { no mês. Desfechos: Bullying físico e verbal. Nenhuma associação para } \\
\text { o papel de vítima. Agressores: OR = 2,44 (IC95\%: 2,11-2,81) para } \\
\text { bullying físico e OR = 2,02 (IC95\%: 1,76-2,30) para bullying verbal. } \\
\text { Entre Agressores-vítimas: OR =1,77 (IC95\%: } 1,51-2,07) \text { para bullying } \\
\text { físico e OR }=1,42 \text { (IC95\%: } 1,24-1,61) \text { para bullying verbal. }\end{array}$ \\
\hline $\begin{array}{l}\text { Rivers et al. } \\
(2009)^{55}\end{array}$ & $\begin{array}{l}\mathrm{N}=2.002 . \text { Escolares } \\
\text { do norte da Inglaterra. } \\
\text { Idade: } 12 \text { a } 16 \text { anos. }\end{array}$ & $\begin{array}{l}\text { Modelo de regressões múltiplas com escore T, ajustado para sexo. } \\
\text { Desfecho: Uso de qualquer substancia na vida. Exposição: papel } \\
\text { social no bullying, incluindo testemunho, sem vítima-agressor: } \\
\text { Correlação positiva para uso de substâncias na vida e os papéis de } \\
\text { agressor }[\beta=0,32(\mathrm{p}<0,001)] \text { e testemunha de bullying }[\beta=0,06 \\
(\mathrm{p}<0,05)] \text {. Não houve correlação para o papel de vítima. }\end{array}$ \\
\hline $\begin{array}{l}\text { Shetgiri et al. } \\
(2012)^{56}\end{array}$ & $\begin{array}{l}\mathrm{N}=13.710 \text { Escolares } \\
\text { participantes do HBSC } \\
\text { (EUA) 2001-2002, do } 6^{\circ} \\
\text { ao } 10^{\circ} \text { ano. }\end{array}$ & $\begin{array}{l}\text { Regressão logística multivariável e Análise de Particionamento } \\
\text { Recursivo (RPA) para bullying como agressor (qualquer, moderado e } \\
\text { frequente) e uso corrente de álcool, tabaco ou outras drogas na vida, } \\
\text { vitimização em bullying, sexo, idade, etnia, depressão, desregulação } \\
\text { emocional, desempenho acadêmico, isolamento social, relação com } \\
\text { colegas, porte de armas, envolvimento em brigas, relações familiares } \\
\text { (FAS): agressor (qualquer padrão): Prevalência (P) = 59,3\% para } \\
\text { fumantes, não vítimas de bullying, que não portaram armas e com } \\
\text { envolvimento em brigas; agressor (moderado): P = 61,4 \% para } \\
\text { álcool mais de } 5 \text { dias na semana, fumantes e que portaram armas; } \\
\text { agressor (frequente): P = 68,4 \% para os que referiram irritabilidade } \\
\text { diária, escore na FAS moderado ou elevado, desempenho acadêmico } \\
\text { acima da média, álcool diário, fumantes e porte de armas. }\end{array}$ \\
\hline $\begin{array}{l}\text { Wang et al. } \\
(2012)^{37}\end{array}$ & $\begin{array}{l}\mathrm{N}=7.508 \text { Escolares de } \\
\text { Columbia (EUA), do } 6^{\circ} \\
\text { ao } 10^{\circ} \text { ano. }\end{array}$ & $\begin{array}{l}\text { Análise de classes latentes (LCA) para tipos de bullying entre } \\
\text { perpetradores e não envolvidos, estratificada por sexo, e comparação } \\
\text { entre proporções para uso de substâncias (cigarro, álcool e maconha } \\
\text { nos últimos } 30 \text { dias) segundo as classes fixadas. Meninos e meninas } \\
\text { perpetradores de todos os tipos de bullying referiram mais uso de } \\
\text { substâncias ( } 61,6 \% \text { e } 50,4 \%) \text {, seguidos por perpetradores de bullying } \\
\text { verbal/relacional ( } 45,9 \% \text { e } 49,2 \%) \text {, quando comparados a meninos e } \\
\text { meninas não envolvidos }(29,8 \% \text { e } 33,9 \%)(p<0,05) \text {. }\end{array}$ \\
\hline
\end{tabular}

Legenda: AOD - Álcool e Outras Drogas; ns - Não Significativa.

blemático de álcool, ou em grandes quantidades, associado a escores mais elevados de perpetração de bullying ${ }^{57}$.
Ainda, o estudo de delineamento qualitativo sugere que o uso de cigarro, álcool e outras substâncias pode ser influenciado pela experiência 
Quadro 3. Estudos Longitudinais que analisaram a relação entre Uso de Substâncias e Envolvimento em Bullying.

\begin{tabular}{|c|c|c|}
\hline Autor/ano & Amostra & Resultados \\
\hline $\begin{array}{l}\text { Espelage et al. } \\
(2014)^{40}\end{array}$ & $\begin{array}{l}\mathrm{N}=1.232 \text { Estudantes do } \\
\text { Centro-Oeste dos EUA. } \\
\text { Idade média: } 13,9 \text { anos. }\end{array}$ & $\begin{array}{l}\text { Modelo de equações estruturais em três momentos ao longo de } \\
\text { um ano, para mediação da perpetração de bullying na relação } \\
\text { entre violência familiar e uso de substâncias no ano. Perpetração } \\
\text { de bullying mediou a relação entre violência familiar e uso de } \\
\text { substâncias (álcool, cigarro ou solventes) apenas para os meninos } \\
{[\beta=0.09(\mathrm{p}<0,05)] \text {. }}\end{array}$ \\
\hline $\begin{array}{l}\text { Farrington e } \\
\text { Ttofi. }(2011)^{42}\end{array}$ & $\begin{array}{l}\mathrm{N}=411 \text { Homens } \\
\text { residentes de Londres. }\end{array}$ & $\begin{array}{l}\text { Regressão logística, multivariável, com diferentes desfechos em } \\
\text { diferentes idades, dos } 8 \text { aos } 50 \text { anos, para perpretação de bullying } \\
\text { (exposição). Praticar bullying aos } 14 \text { anos foi preditor de uso de } \\
\text { drogas entre } 27 \text { aos } 32 \text { anos de idade }[\mathrm{OR}=2,44(\mathrm{p}=0,010)] \text {. }\end{array}$ \\
\hline $\begin{array}{l}\text { Forster et al. } \\
(2013)^{44}\end{array}$ & $\begin{array}{l}\mathrm{N}=1.167 \text { Escolares } \\
\text { hispânicos e latinos da } \\
\text { Califórnia (EUA). }\end{array}$ & $\begin{array}{l}\text { Regressão logística. Exposição: vitimização por bullying no mês, } \\
\text { em T1 (90 ano). Desfecho: uso de álcool, tabaco e maconha no } \\
\text { mês, em T2 (10 ano). Associação significativa para tabagismo: } \\
\text { OR = 1,26 (IC95\%: 1,04-1,52), seguido de Análise de Mediação, } \\
\text { com vitimização em T1 mediando a relação entre coesão familiar e } \\
\text { tabagismo em T2 }(\beta=-0,13 ; \mathrm{p}<0,001) \text {. }\end{array}$ \\
\hline $\begin{array}{l}\text { Hemphill } \\
\text { et al. } \\
(2011)^{39}\end{array}$ & $\begin{array}{l}\mathrm{N}_{\mathrm{T} 1}=907 \text { Escolares de } \\
\text { Victoria (Australia), do } \\
5^{\circ} \text { ano escolar. }\end{array}$ & $\begin{array}{l}\text { Análise de regressão logística ajustada para variáveis independentes. } \\
\text { Exposições: vitimização e perpetração de bullying no } 7^{\circ} \text { e no } 10^{\circ} \\
\text { anos. Desfechos de interesse: uso de maconha no mês e uso de } \\
\text { álcool nas últimas } 2 \text { semanas. Associação significativa apenas para } \\
\text { uso de Álcool no } 11^{\circ} \text { ano por agressores no } 10^{\circ} \text { ano, comparados } \\
\text { aos não envolvidos: OR = 1,67 (IC95\%: } 1,12-2,50 \text { ). }\end{array}$ \\
\hline $\begin{array}{l}\text { Klomek et al. } \\
(2013)^{45}\end{array}$ & $\begin{array}{l}\mathrm{N}=2.342 \text { Escolares do } \\
\text { Estado de Nova York. } \\
\text { Idade média: } 14,8 \text { anos. }\end{array}$ & $\begin{array}{l}\text { Test T para amostras pareadas, comparando grupos com riscos } \\
\text { psíquicos (que incluia uso de substâncias - AOD) expostos e não } \\
\text { expostos a bullying em follow-up de } 2 \text { anos. } \\
\text { Baseline: Agressores com escore maior para AOD }(\mathrm{m}=5,4 ; \mathrm{dp}= \\
5,9) \text { que não envolvidos }(\mathrm{m}=2,7 ; \mathrm{dp}=3,5)(\mathrm{p}<0,01) \text {. Outros } \\
\text { papéis, comparados a não envolvidos: ns. Nenhuma diferença no } \\
\text { Follow-up. }\end{array}$ \\
\hline $\begin{array}{l}\text { Low e } \\
\text { Espelage. } \\
(2013)^{41}\end{array}$ & $\begin{array}{l}\mathrm{N}=1.023 \text { Escolares } \\
\text { (EUA). } \\
\text { Idade: } 10 \text { a } 15 \text { nos. }\end{array}$ & $\begin{array}{l}\text { Análise de correlação entre envolvimento em bullying verbal e } \\
\text { relacional como agressor no mês, em T1 e T3, e uso de AOD em T2. } \\
\text { Bullying verbal/relacional (T1) X AOD (T2): } \rho=0,35(\mathrm{p}<0,01) \text {. } \\
\text { Bullying verbal/relacional (T3) X AOD (T2): } \rho=0,41(\mathrm{p}<0,01) \text {. }\end{array}$ \\
\hline
\end{tabular}

pessoal de sofrer algum tipo de bullying ${ }^{58}$. Apontou, ainda, o uso de maconha como atividade social, favorecendo a integração dos adolescentes com seus pares e a sensação de proteção e segurança dentro do ambiente escolar, quando este é percebido como hostil (Quadro 4).

Embora não seja foco deste estudo analisar os fatores associados à relação entre bullying e uso de drogas, alguns resultados chamaram a atenção e merecem ser destacados. Ainda que a maioria dos estudos de delineamento transversal não tenha encontrado diferenças significativas entre meninos e meninas quanto à associação entre bullying e uso de substâncias, outros estudos evidenciaram diferenças entre adolescentes de ambos os sexos. Por exemplo, Pierobon et al..$^{23}$ identificaram relação significativa e expressiva entre vitimização e uso de álcool no mês para ambos os sexos. Contudo, as meninas apresentaram quase o dobro de chance de usar álcool no mês em relação aos meninos. Já no estudo de Garcia-Continente et al. ${ }^{31}$, meninas vítimas apresentaram menor chance de uso de álcool nos últimos 6 meses. Entre meninos e meninas internados em hospital psiquiátrico, Luukkonen et al. ${ }^{36}$ encontraram chance aumentada para uso de maconha e outras drogas apenas entre as meninas agressoras e, para uso de álcool, apenas entre os meninos, enquanto Garcia-Continente et al. ${ }^{31}$ encontraram menor chance de uso na vida de maconha pelos meninos vitimizados.

Ainda que os autores utilizem análises estatísticas distintas, é possível estimar a magnitude das associações aqui estudadas, pelo menos para 
Quadro 3. continuação

\begin{tabular}{|c|c|c|}
\hline Autor/ano & Amostra & Evidências \\
\hline $\begin{array}{l}\text { Niemelä et al. } \\
(2011)^{38}\end{array}$ & $\begin{array}{l}\mathrm{N}=2.946 \text { Meninos } \\
\mathrm{T} 1 \text { aos } 8 \text { anos e T2 no } \\
\text { serviço militar (18 anos) } \\
\text { na Finlândia. }\end{array}$ & $\begin{array}{l}\text { Regressão logística para uso frequente de álcool, tabagismo pesado } \\
\text { e uso de drogas ilícitas aos } 18 \text { anos, entre envolvidos em bullying } \\
\text { aos } 8 \text { anos, ajustada para estrutura familiar, papel no bullying, nível } \\
\text { educacional dos pais, Escore de Rutter (morbidade infantil), Escore } \\
\text { no YASR (morbidade na adolescência) e uso de outras substâncias. } \\
\text { Associação significativa para agressores eventuais e uso frequente } \\
\text { de cigarro [OR }=1,7 \text { (IC95\%: } 1,2-2,3 \text { )] e drogas ilícitas [OR }=1,7 \\
\text { (IC95\%: } 1,2-2,3 \text { )], agressores frequentes e uso de drogas ilícitas } \\
\text { [OR = 2,5 (IC95\%: } 1,2-5,4)] \text {, vitimização frequente e uso frequente } \\
\text { de cigarro [OR }=1,8(\text { IC95\%: } 1,1-2,8)] \text {. }\end{array}$ \\
\hline $\begin{array}{l}\text { Tharp-Taylor } \\
\text { et al. }(2009)^{46}\end{array}$ & $\begin{array}{l}\mathrm{N}=926 \text { Escolares da } \\
\text { Califórnia. } \\
\text { Idade: } 11 \text { a } 14 \text { anos. }\end{array}$ & $\begin{array}{l}\text { Regressão logística para uso de uso AOD no mês em T2 } \\
\text { (primavera de 2005) segundo vitimização por bullying (físico-BF } \\
\text { e psíquico-BP) no ano em T1 (outono de 2004): todos associados } \\
\text { significativamente, variando de álcool e BF: RR = 1,62 (IC95\%: } \\
\text { 1,02-2,57) até maconha e BP: RR = 3,56 (IC95\%: 1,43-8,85). Efeito } \\
\text { de BF mais evidente entre meninas que meninos para álcool, } \\
\text { maconha e inalantes. }\end{array}$ \\
\hline $\begin{array}{l}\text { Topper et al. } \\
(2011)^{47}\end{array}$ & $\begin{array}{l}\mathrm{N}=324 \text { Escolares de } \\
\text { Londres (Inglaterra). } \\
\text { Idade em T1: } 13 \text { a } 15 \\
\text { anos; T2: } 1 \text { ano depois. }\end{array}$ & $\begin{array}{l}\text { Correlação de Pearson para vitimização, uso e problemas devido } \\
\text { ao uso de álcool nos últimos } 6 \text { meses. Vitimização em T1 esteve } \\
\text { significativamente relacionada aos escores para uso de álcool } \\
(\mathrm{r}=0,13, \mathrm{p}<0,05) \text { e problemas devido ao uso de álcool }(\mathrm{r}=0,22 \text {, } \\
\mathrm{p}<0,001) \text { em T2. Já o uso e os problemas devido ao uso de álcool } \\
\text { em T1 não estiveram significativamente relacionados aos escores } \\
\text { para vitimização em T2. }\end{array}$ \\
\hline $\begin{array}{l}\text { Weiss et al. } \\
(2011)^{43}\end{array}$ & $\begin{array}{l}\mathrm{N}=1.771 \text { Escolares da } \\
\text { California (EUA), T1: } \\
6^{\circ} \text { ano, T2: } 7^{\circ} \text { ano, } \mathrm{T} 3: \\
8^{\circ} \text { ano. }\end{array}$ & $\begin{array}{l}\text { Modelo linear generalizado misto. Exposição: Papéis sociais agressor } \\
\text { e agressor-vítima. Desfecho: ter iniciado o uso de tabaco no } 8^{\circ} \text { ano. } \\
\text { Nenhuma associação para comportamento agressor. Agressores- } \\
\text { vítimas no } 6^{\circ} \text { ano predominaram entre os que iniciaram uso de } \\
\text { tabaco no } 7^{\circ} \text { e } 8^{\circ} \text { ano }(F=5,85, p<0,05) \text {. }\end{array}$ \\
\hline
\end{tabular}

Legenda: AOD - Álcool e Outras Drogas; ns - Não Significativa.

papéis sociais que envolvem o comportamento agressor. Comparados a não envolvidos, foram estimadas Razões de Chance (OR) de 2,44 (IC95\%: 2,11-2,81) para uso de álcool no mês entre agressores de bullying físico ${ }^{34}$, e até 5,00 (IC95\%: 2,71-9,25) para uso corrente de álcool entre agressores por racismo ${ }^{29}$. Para tabaco, as OR variaram entre 1,7 (IC95\%: 1,2-2,3) para uso frequente ${ }^{38}$ e 2,66 (IC95\%: 2,229-3,167) para uso no mês ${ }^{24}$. Em relação ao uso de maconha no mês, a variação foi de 1,53 (IC95\%: 1,44-1,63) a 2,84 (IC95\%: 2,50-3,23) 51 . O estudo de Luukkonen et al. ${ }^{36}$ evidenciou OR bastante distintas destas (Quadro 2), com diferenças entre meninos e meninas, mas seus dados se limitaram a jovens hospitalizados por patologias psiquiátricas, ao contrário dos demais estudos, que entrevistaram escolares.

\section{Discussão}

A partir da exposição dos principais achados, considera-se que o estudo atendeu aos objetivos propostos, trazendo resultados e descobertas importantes sobre a relação entre os processos de bullying e o uso de substâncias psicoativas. Fenômenos bastante frequentes na adolescência e que merecem ser estudados nos dias atuais, parecem somar-se ou potencializarem-se enquanto fatores de risco ao desenvolvimento durante essa etapa da vida ${ }^{12,24,29,30,38}$. Os estudos aqui analisados, em sua maioria de delineamento quantitativo transversal, com amostras de escolares, tanto meninas quanto meninos, evidenciam a associação entre praticar o bullying e fazer uso de substâncias, independente do sexo. O mesmo não se pode afirmar em relação à vitimização por bullying e o uso de substâncias, tema onde persistem controvérsias. Há estudos apontando para a inexistência de associação entre os fenômenos da vitimização 
Quadro 4. Estudos com outros delineamentos que analisaram a relação entre Uso de Substâncias e Envolvimento em Bullying.

\begin{tabular}{|c|c|c|}
\hline Autor/ano & Amostra & Resultados \\
\hline $\begin{array}{l}\text { Archimi e } \\
\text { Kuntsche. } \\
(2014)^{54}\end{array}$ & $\begin{array}{l}\mathrm{N}=2.548 \text { Escolares da } \\
\text { Suiça. } \\
\text { Idade: } 12 \text { a } 17 \text { anos. }\end{array}$ & $\begin{array}{l}\text { Análise por modelo de equações estruturais, com dados de estudo } \\
\text { transversal, estratificada por sexo. Exposição principal: papéis } \\
\text { sociais no bullying comparados a não referir bullying. Desfecho: } \\
\text { consumo de álcool no presente: } \\
\text { Meninos }\left(\mathrm{R}^{2}=9,6 \%\right) \text { : Agressores }[\beta=0,368(0,057)] \text {, Vítimas } \\
{[\beta=-0,279(0,082)] \text { e Vítimas-Agressores }[\beta=0,290(0,126)]} \\
\text { Meninas }\left(\mathrm{R}^{2}=8,4 \%\right) \text { : Agressoras }[\beta=0,559(0,079)], \text { Vítimas } \\
{[\beta=-0,003(0,081)] \text { e Vítimas-Agressoras }[\beta=0,490(0,001)]} \\
\text { Modelo com motivos para beber }(\mathrm{DMQ} \text {-RSF): Meninos } \\
\left(\mathrm{R}^{2}=44,0 \%\right) \text { e Meninas }\left(\mathrm{R}^{2}=44,3 \%\right) \text {. }\end{array}$ \\
\hline $\begin{array}{l}\text { Ferret et al. } \\
(2011)^{57}\end{array}$ & $\begin{array}{l}\mathrm{N}=140 \text { Escolares da } \\
\text { África do Sul. } \\
\text { Idade média: } 14,77 \text { anos. }\end{array}$ & $\begin{array}{l}\text { Estudo quase experimental. Exposição: Consumo de álcool - } \\
\text { Compara grupo de estudantes com problemas por uso de álcool } \\
\text { (consumo na vida de mais de } 100 \text { unidades de bebida alcoólica e } \\
\text { diagnóstico de abuso ou dependência de álcool segundo o DSM-IV) } \\
\text { com pares não usuários. Escore para envolvimento em bullying - } \\
\text { agressor: Estudantes com problemas por uso de álcool: } \mathrm{m}=11,94 ; \\
\mathrm{dp}=11,89 ; \text { Estudantes do grupo controle: } \mathrm{m}=4,89 ; \mathrm{dp}=7,34 ; \\
\text { ANOVA: } \mathrm{F}=19,42(\mathrm{p}<0,001)\end{array}$ \\
\hline $\begin{array}{l}\text { Fletcher et al. } \\
(2009)^{58}\end{array}$ & $\begin{array}{l}\mathrm{N}=30 \text { Escolares de } \\
\text { Londres. }\end{array}$ & $\begin{array}{l}\text { Qualitativo, por análise de conteúdo e grounded theory. Alguns } \\
\text { estudantes, que perceberam a escola como um lugar assustador, } \\
\text { de práticas de bullying e outras formas de violência, parecem ter } \\
\text { feito uso de maconha como atividade social, a fim de se sentirem } \\
\text { integrados e seguros com o grupo de jovens e, assim, se protegerem. }\end{array}$ \\
\hline $\begin{array}{l}\text { Hanewinkel et } \\
\text { al. }(2010)^{53}\end{array}$ & $\begin{array}{l}\mathrm{N}=3.440 \text { Escolares da } \\
\text { Alemanha. } \\
\text { Idade: } 11 \text { a } 16 \text { anos. }\end{array}$ & $\begin{array}{l}\text { Ensaio clínico randomizado para programa de prevenção que } \\
\text { desestimula o tabagismo. Regressão logística ordinal para estimar } \\
\text { associação entre bullying e tabagismo no ingresso no estudo, } \\
\text { ajustada para idade, sexo e nacionalidade. Modelos lineares } \\
\text { generalizados mistos para estimar se a intervenção determinaria } \\
\text { aumento na ocorrência do bullying. Análise para os papéis de } \\
\text { agressor e vítima de bullying nos últimos } 60 \text { dias entre fumantes em } \\
\text { uso diário, comparados a não fumantes: nenhuma associação para } \\
\text { tabagismo e vitimização; OR para agressão = 4,66 (IC95\%: 3,38- } \\
\text { 6,43). Nenhuma modificação detectada para o registro de bullying } \\
\text { após a intervenção. }\end{array}$ \\
\hline $\begin{array}{l}\text { Litwiller e } \\
\text { Brausch. } \\
(2013)^{49}\end{array}$ & $\begin{array}{l}\mathrm{N}=4.693 \text { Escolares de } \\
27 \text { escolas rurais (EUA). } \\
\text { Idade: } 14 \text { a } 19 \text { anos. }\end{array}$ & $\begin{array}{l}\text { Análise de mediação Exposição: vitimização por bullying. Desfecho: } \\
\text { comportamento suicida. Intervenientes: Uso de substâncias, } \\
\text { Violência, Comportamento sexual. } \\
\text { Correlação entre bullying e uso de substâncias }=0,70(p<0,001) \text {. }\end{array}$ \\
\hline $\begin{array}{l}\text { Luk et al. } \\
(2010)^{10}\end{array}$ & $\begin{array}{l}\mathrm{N}=1.495 \text { Escolares } \\
\text { norte-americanos. } \\
\text { Idade média }=16,1 \\
\text { anos. }\end{array}$ & $\begin{array}{l}\text { Análise por modelo de equações estruturais com múltiplos grupos, } \\
\text { com dados de estudo transversal, estratificada por sexo, para a } \\
\text { relação entre vitimização por bullying em } 60 \text { dias, depressão em } \\
30 \text { dias e uso de substâncias em } 30 \text { dias. Para meninos: vitimização } \\
\text { carrega para depressão }(\beta=0,380 ; p<0,001) \text { e para uso de } \\
\text { substâncias ( } \beta=0,332 ; p<0,001) \text { e depressão não carrega para uso } \\
\text { de substâncias }(\beta=0,052 ; p=0,289) \text {; Para meninas: vitimização } \\
\text { carrega para depressão }(\beta=0,422 ; p<0,001) \text { e depressão } \\
\text { carrega para uso de substâncias ( } \beta=0,261 ; p=0,003) \text {, enquanto } \\
\text { vitimização não carrega para uso de substâncias }(\beta=0,069 ; \\
p=0,223) \text {. }\end{array}$ \\
\hline
\end{tabular}

por bullying e o uso de substâncias, bem como estudos que propõem associação ou associação inversa.
É limitação deste estudo o número de bases de dados eletrônicos visitadas. Foram escolhidas bases consideradas de referência para publicações 
científicas na área deste estudo e a investigação se estendeu ao limite da capacidade operacional da equipe, cobrindo sete bases, em sua totalidade, para um intervalo de seis anos completos. É possível que alguma publicação relevante esteja indexada em bases não consultadas, mas o grande número de registros repetidos, equivalendo a $41 \%$ do total de artigos inicialmente selecionados, é indicativo de um bom nível de saturação na busca.

Além disso, devido ao grande número de registros incluídos a partir da busca nas bases, não foi realizada a busca de artigos a partir das referências dos artigos selecionados. Tal decisão foi tomada devido ao entendimento de que já havia um número expressivo de publicações e que os achados em análise atendiam os objetivos da revisão, como sugerido em alguns protocolos de revisões sistemáticas ${ }^{59}$.

Outro fato a ser destacado refere-se aos quatro artigos excluídos por não apresentarem o conceito de bullying utilizado. É possível que os dados deixados de fora deste estudo apresentem relevância científica e contribuam para a elucidação da relação entre vitimização e uso de substâncias, uma vez que todos apontam para aumento do uso de álcool e outras drogas entre vítimas de bullying ${ }^{60-63}$. No entanto, assumiu-se este risco por considerar-se que, além da não explicitação do conceito, a forma como o fenômeno bullying foi investigado difere significativamente da forma como os artigos incluídos nesta análise procederam. Assim, a inclusão desses artigos poderia comprometer a comparabilidade dos dados.

Os estudos aqui analisados foram publicados em periódicos que utilizam o processo de revisão por pares para a sua publicação. Apresentam de forma clara os métodos utilizados, com processos de amostragem e mensuração dos dados adequados aos objetivos propostos, tendo sido, por isso, considerados satisfeitos os critérios mínimos de qualidade exigidos para sua inclusão nesta revisão.

Parece suficientemente demostrada a associação entre o envolvimento em situações de bullying em um papel que envolva a sua perpetração (agressor ou agressor-vítima) e o uso de substâncias psicoativas por adolescentes de ambos os sexos. Tal evidência contraria a menor atenção dada aos agressores. Isto pode ocorrer por questões culturais e por um entendimento equivocado de que estes jovens não sofrem ou que apenas obtêm prazer e ganhos com as agressões, o que faz com que mais frequentemente as intervenções sejam direcionadas para a compreensão das vítimas ${ }^{64}$.
Divergências entre os estudos foram evidenciadas no que se refere à associação entre vitimização por bullying e uso de substâncias, com resultados que apontam para uma associação inversa entre os fenômenos, outros que mostram associação direta e, ainda, estudos que indicam a ausência de associação entre eles. Desta forma, não é possível precisar como é a relação entre vitimização por bullying e uso de substâncias psicoativas na adolescência a partir desta revisão. Estas evidências reforçam a necessidade de novos estudos empíricos, que investiguem e aprofundem o entendimento da associação entre estas duas condições de risco para adolescentes ${ }^{1-4}$.

Ressalta-se que esta divergência de resultados pode ter sido influenciada por alguns aspectos, os quais devem ser destacados. Primeiramente, embora todos os estudos analisados tenham entrevistado adolescentes, em geral estudantes, nota-se que os mesmos apresentam amostras com características diferentes. Ou seja, há dados que foram coletados exclusivamente com adolescentes hospitalizados, assim como observa-se amostras exclusivamente masculinas, que apresentam diferenças socioculturais e etárias. Desse modo, há evidências de que adolescentes mais jovens, provavelmente por apresentarem menos recursos cognitivos e emocionais, estejam em maior risco em relação aos prejuízos associados ao envolvimento com o bullying, entre eles o uso de substâncias ${ }^{51}$. Por outro lado, vítimas de bullying com maior idade apesentaram maior chance de uso de álcool, tabaco e maconha que os mais novos, conforme indicado por Luk et al. ${ }^{48}$ Há, também, indícios de que a existência de sofrimento psíquico interfira na associação entre os fenômenos $^{36,38,56,64}$, assim como a etnia ${ }^{27,35,48,56}$. Além disso, os instrumentos utilizados para a mensuração dos fenômenos de interesse nesta revisão são distintos entre os estudos que divergem sobre a relação entre vitimização e uso de substâncias, além de investigarem aspectos diferentes do fenômeno bullying. Assim, é possível que a falta de equiparação entre os instrumentos justifique em parte as diferenças encontradas.

Alguns estudos chamam a atenção também ao indicar outras condições que parecem modificar o efeito do envolvimento em bullying sobre o uso de álcool e outras drogas. Para Archimi e Kuntsche $e^{54}$, resultados diferentes na associação entre bullying e uso de substâncias foram encontrados quando se consideravam diferentes motivos para o uso de álcool (sociais, de reforçamento, coping e conformidade). Já Garcia-Continente et al. ${ }^{31}$ sugeriram o uso social da maconha 
como proteção à vitimização por bullying, talvez pelo fato de a vitimização implicar exclusão dos grupos, reduzindo a oferta de drogas pelos pares. Como o estudo é transversal, pensando em reversibilidade causal, também se pode imaginar que o uso da substância se associa a maiores níveis de socialização e formação de vínculos com pares, protegendo seus membros da condição de vitimização por bullying. Por fim, Shetgiri et al. ${ }^{56}$ evidenciaram que, entre os adolescentes que se envolveram em brigas, não carregaram armas e não foram vítimas de bullying, mas fumaram, a prevalência de perpetração de bullying foi significativamente maior do que entre aqueles adolescentes que não fumaram. A partir desses resultados, é possível pensar a complexidade que envolve os fenômenos aqui estudados, ou seja, os diferentes fatores que se associam à relação entre eles, nem sempre contemplados nos estudos aqui analisados.

Outro aspecto a ser destacado refere-se ao delineamento dos estudos. O fato de a maioria das investigações apresentar delineamento quantitativo transversal permite-nos verificar associações entre os fenômenos bullying e uso de substâncias psicoativas na adolescência, mas pouco poder dizer a respeito de relações de causa e efeito entre eles. Particularmente, faz-se importante compreender o que leva a uma associação positiva entre os fenômenos, assim como o que protege adolescentes vitimizados de se envolverem com o uso de substâncias (associação negativa e ausência de associação), a fim de que estratégias de intervenção adequadas sejam planejadas.

\section{Considerações Finais}

Apesar da divergência quanto à vitimização em bullying, é possível afirmar que adolescentes envolvidos em situações de bullying, em qualquer papel social que envolva a agressão, fazem mais uso de substâncias psicoativas em comparação àqueles não envolvidos. Mais especificamente, os adolescentes agressores tendem a ser os que mais fazem tal uso. Essa conclusão aponta para um foco relevante para a intervenção psicológica, pois enfatiza uma maior vulnerabilidade dos adolescentes nesta condição e, portanto, a maior necessidade de atenção e proteção desses jovens. A associação entre estes fenômenos também serve de alerta para o seu diagnóstico precoce em adolescentes. Ainda que não possa ser tomado como regra, indícios de envolvimento em situações de bullying servem como alerta para um possível uso de substâncias psicoativas e viceversa.

Ressalta-se, ainda, que as inconsistências entre os estudos no que se refere ao comportamento das vítimas podem traduzir o efeito da subjetividade desses jovens sobre as situações externas vivenciadas. Novos estudos empíricos com adolescentes vítimas de bullying são, portanto, necessários, a fim de fornecer subsídios para o preenchimento desta lacuna e avançar para além dos resultados já existentes, que, de certa forma, legitimam a dicotomia entre vítima e agressor e subestimam o sofrimento de ambos. 


\section{Colaboradores}

CL Horta trabalhou na concepção, pesquisa, metodologia e redação final. RL Horta e CSM Lisboa trabalharam na concepção, metodologia e redação final. A Mester, D Lindern e JLA Werber trabalharam na pesquisa e redação final. DC Levandowski trabalhou na metodologia e redação final.

\section{Agradecimentos}

À CAPES, pela bolsa de Doutorado de Cristina Lessa Horta. Ao CNPq, pelas bolsas de Mestrado de Daniele Lindern e João Luís Almeida Weber e pela Bolsa de Produtividade em Pesquisa de Carolina Saraiva de Macedo Lisboa.

\section{Referências}

1. Carlini EA, Noto AR, Sanchez ZM, Carlini CMA, Locatelli DP, Abeid LR, Amato TC, Opaleye ES, Tondowski CS, Moura YG. VI Levantamento Nacional sobre o Consumo de Drogas Psicotrópicas entre Estudantes do Ensino Fundamental e Médio das Redes Pública e Privada de Ensino nas 27 Capitais Brasileiras. São Paulo: CEBRID/ UNIFESP; 2010.

2. Craig W, Harel-Fish Y, Fogel-Grinvald H, Dostaler S, Hetland J, Simons-Morton B, Molcho M, Mato MG, Overpeck M, Due P, Picket, W, HBSC Violence \& Injuries Prevention Focus Group, HBSC Bullying Writing Group. A cross-national profile of bullying and victimization among adolescents in 40 countries. Int J Public Health 2009; 54(Supl. 2):S216-S224.

3. Malta DC, Mascarenhas MDM, Porto DL, Duarte EA, Sardinha LM, Barreto SM, Neto OLM. Prevalência do consumo de álcool e drogas entre adolescentes: análise dos dados da Pesquisa Nacional de Saúde Escolar. Rev Bras Epidemiol 2011; 14(1):136-146.

4. Nansel TR, Craig W, Overpeck MD, Saluja G, Ruan J. The Health Behavior in School-aged Children Bullying Analyses Working Group. Cross-national consistency in the relationship between bullying behaviors and psychosocial adjustment. Arch Pediatr Adolesc Med 2004; 158(8):730-736.

5. Shek DTL, Ma HK, Sun RCF. A brief overview on adolescent developmental problems in Hong Kong. ScientificWorldJournal 2011; 11:2243-2256.

6. Brasil. Ministério da Saúde (MS). Diretrizes nacionais para a atenção integral à saúde de adolescentes e jovens na promoção, proteção e recuperação da saúde. Brasília: MS; 2010.

7. Braga LL, Lisboa C. Estratégias de coping para lidar com o processo de bullying: um estudo qualitativo. $R$ Interam Psicol 2010; 44(2):321-331.

8. Malta DC, Silva MAI, Mello FCM, Monteiro RA, Sardinha LMV, Crespo C, Carvalho MGO, Silva MMA, Porto DL. Bullying nas escolas brasileiras: resultados da Pesquisa Nacional de Saúde do Escolar (PeNSE), 2009. Cien Saude Colet 2010; 15(2):3065-3076.

9. Olweus D. Bullying at school: What we know and what we can do. London: Blackwell; 1993.

10. Luk JW, Wang J, Simons-Morton BG. Bullying victimization and substance use among U. S. adolescents: mediation by depression. Prev Sci 2010; 11(4):355-359.

11. Cruzeiro AL, Silva RA, Horta BL, Souza LD, Faria AD, Pinheiro RT, Silveira Ide O, Ferreira CD. Prevalência e fatores associados ao transtorno da conduta entre adolescentes: um estudo de base populacional. Cad Saude Publica 2008; 24(9):2013-2020.

12. Radliff KM, Wheaton JE, Robinson K, Morris J. Illuminating the relationship between bullying and substance use among middle and high school youth. Addict Behav 2012; 37(4):569-572.

13. Carlini EA, Galduróz JC, Silva AAB, Noto AR, Fonseca AM, Carlini CM, Oliveira LG, Nappo SA, Moura YG, Sanchez ZM. II Levantamento domiciliar sobre o uso de drogas psicotrópicas no Brasil: estudo envolvendo as 108 maiores cidades do país. São Paulo: CEBRID/UNIFESP; 2006.

14. Horta RL, Horta BL, Horta CL. Uso de drogas e sofrimento psíquico numa instituição universitária do Sul do Brasil. Psicol Rev (Online) 2012; 18(2):264-276. 
15. Peuker AC, Fogaça J, Bizarro LA. Expectativas e beber problemático entre universitários. Psic: Teor Pesq 2006; 22(2):193-200.

16. Acosta LD, Fernández AR, Pillon SC. Factores sociales para el uso de alcohol en adolescentes y jóvens. Rev Latinoam Enfermagem 2011; 19(Spec. No):771-781.

17. Vieira PC, Aerts DRGC, Freddo SL, Bittencourt A, Monteiro L. Uso de álcool, tabaco e outras drogas por adolescentes escolares em município do Sul do Brasil. Cad Saude Publica 2008; 24(11):2487-2498.

18. Moher D, Liberati A, Tetzlaff J, Altman DG; PRISMA Group. Preferred Reporting Items for Systematic Reviews and Meta-Analyses: The PRISMA Statement. Int J Surg 2010; 8(5):336-341.

19. Urrútia G, Bonfill X. Declaración PRISMA: una propuesta para mejorar la publicación de revisiones sistemáticas y metanálisis. Med Clin (Barc) 2010, 135(11):507-511.

20. Viswanathan M, Ansari MT, Berkman ND, Chang S, Hartling L, McPheeters M, Santaguida PL, Shamliyan T, Singh K, Tsertsvadze A, Treadwell JR. Assessing the Risk of Bias of Individual Studies in Systematic Reviews of Health Care Interventions. Guide for Comparative Effectiveness Reviews. AHRQ WebM\&M 2012; 10(14):193-221.

21. McGee E, Valentine C, Schulte M, Brown SA. Peer victimization and alcohol involvement among adolescents self-selecting into a school-based alcohol intervention. J Child Adolesc Subst Abuse 2011; 20:253-269.

22. Pan SW, Spittal PM. Health effects of perceived racial and religious bullying among urban adolescents in China: A cross-sectional national study. Glob Public Health 2013; 8(6):685-697.

23. Pierobon M, Barak M, Hazrati S, Jacobsen KH. Alcohol consumption and violence among argentine adolescents. J Pediatr 2013; 89(1):100-107.

24. Bradshaw CP, Waasdorp TE, Goldweber A, Johnson SL. Bullies, gangs, drugs, and school: understanding the overlap and the role of ethnicity and urbanicity. J Youth Adolescence 2013; 42(2):220-234.

25. Tee GH, Kaur G. Correlates of current smoking among malaysian secondary school children. Asia Pac J Public Health 2014; 26(5S):70S-80S.

26. Silva RA, Cardoso TA, Jansen K, Souza LD, Godoy RV, Cruzeiro AL, Horta BL, Pinheiro RT. Bullying and associated factors in adolescents aged 11 to 15 years. Trends Psychiatry Psychother 2012; 34(1):19-24.

27. Ringwalt C, Shamblen S. Is there an association between adolescent bullying victimization and substance abuse? J drug educ 2012; 42(4):447-467.

28. Espelage DL, Low S, De La Ru L. Relations Between Peer Victimization Subtypes, Family Violence, and Psychological Outcomes During Early Adolescence. Psychol Violence 2012; 2(4):313-324.

29. Vieno A, Gini G, Santinello M. Different forms of bullying and their association to smoking and drinking behavior in Italian adolescents. J Sch Health 2011; 81(7):393-399.
30. Yen CF, Yang P, Wang PW, Lin HC, Liu TL, Wu Y-Y, Tang TC. Association between school bullying levels/ types and mental health problems among Taiwanese adolescents. Compr Psychiatry 2014; 55(3):405-413.

31. Garcia-Continente X, Pérez-Giménez A, Adell MN. Factores relacionados com el acoso escolar (bullying) em los adolescentes de Barcelona. Gac Sanit 2010; 24(2):103-108.

32. Garcia-Continente X, Pérez-Giménez A, Espelt A. Adell, MN. Bullying among schoolchildren: differences between victims and agressors. Gac Sanit 2013; 27(4):350-354.

33. McMahon EM, Reulbach U, Keeley H, Perry IJ, Arensman E. Bullying victimization, self harm and associated factors in Irish adolescent boys. Soc Sci Med 2010; 71(7):1300-1307.

34. Fossati A, Borroni S, Maffei C. Bullying as a style of personal relating: Personality characteristics and interpersonal aspects of self-reports of bullying behaviours among Italian adolescent high school students. Personal Ment Health 2012; 6(4):325-339.

35. Peleg-Oren N, Cardenas GA, Comerford M, Galea S. An association between bullying behaviors and alcohol use among middle school students. J Early Adolesc 2010; 32(6):761-775.

36. Luukkonen AH, Riala K, Hakko H, Räsänen P; Study-70 workgroup. Bullying behaviour and substance abuse among underage psychiatric inpatient adolescents. Eur Psychiatry 2010; 25(7):382-389.

37. Wang J, Iannotti RJ, Luk JW. Patterns of adolescent bullying behaviors: physical, verbal, exclusion, rumor, and cyber. J Sch Psychol 2012; 50(4):521-534.

38. Niemelä S, Brunstein-Klomek A, Sillanmäki L, Helenius H, Piha J, Kumpulainen K, Moilanen I, Tamminen T, Almqvist F, Sourander A. Childhood bullying behaviors at age eight and substance use at age 18 among males. A Nationwide prospective study. Addict Behav 2011; 36(3):256-260.

39. Hemphill SA, Kotevski A, Herrenkohl TI, Bond L, Kim MJ, Toumbourou JW, Catalano RF. Longitudinal consequences of adolescent bullying perpetration and victimisation: a study of students in Victoria, Australia. Crim Behav Ment Health 2011; 21(2):107-116.

40. Espelage DL, Low S, Rao MA, Hong JS, Little TD. Family violence, bullying, fighting, and substance use among adolescents: a longitudinal mediational model. J Res Adolesc 2014; 24(2):337-349.

41. Low S, Espelage D. Differentiating cyber bullying perpetration from non-physical bullying: commonalities across race, individual, and family predictors. Psychol Violence 2013; 3(1):39-52.

42. Farrington DP, Ttofi MM. Bullying as a predictor of offending, violence and later life outcomes. Crim Behav Ment Health 2011; 21(2):90-98.

43. Weiss JW, Cen S, Mouttapa M, Johnson AC, Unger J. Longitudinal effects of hostility, depression, and bullying on adolescent smoking initiation. J Adolesc Health 2011; 48(6):591-596. 
44. Forster M, Dyal SR, Baezconde-Garbanati L, Chou CP, Soto DW, Unger JB. Bullying victimization as a mediator of associations between cultural/familial variables, substance use, and depressive symptoms among Hispanic youth. Ethn health 2013; 18(4):415-432.

45. Klomek AB, Kleinman M, Altschuler E, Marrocco F, Amakawa L, Gould MS. Suicidal Adolescents' Experiences With Bullying Perpetration and Victimization during High School as Risk Factors for Later Depression and Suicidality. J Adolesc Health 2013; 53(Supl.):S37-S42.

46. Tharp-Taylor S, Haviland A, D'Amico EJ. Victimization from Mental and Physical Bullying and Substance Use in Early Adolescence. Addict Behav 2009; 34(6-7):561567.

47. Topper LR, Castellanos-Ryan N, Mackie C, Conrod PJ. Adolescent bullying victimization and alcohol-related problem behaviour mediated by coping drinking motives over a 12 month period. Addict Behav 2011; 36(12):6-13.

48. Luk JW, Wang J, Simons-Morton BG. The co-occurrence of substance use and bullying behaviors among U.S. adolescents: understanding demographic characteristics and social influences. J Adoles 2012; 35(5):1351-1360.

49. Litwiller BJ, Brausch AM. Cyber bullying and physical bullying in adolescent suicide: the role of violent behavior and substance use. J Youth Adolescence 2013; 42(5):675-684.

50. Cerezo F, Méndez I. Conductas de riesgo social y de salud em adolescentes. Propuesta de intervención contextualizada para un caso de bullying. Anales de Psicología 2012; 28(3):705-719.

51. Gower AL, Borowsky IW. Associations between frequency of bullying involvement and adjustment in adolescence. Acad Pediatr 2013; 13(3):214-221.

52. King CA, Horwitz A, Berona J, Jiang Q. Acutely suicidal adolescents who engage in bullying behavior: 1-year trajectories. J Adolesc Health 2013; 53(Supl. 1):S43-S50.

53. Hanewinkel R, Isensee B, Maruska K, Sargent JD, Morgenstern M. Denormalising smoking in the classroom: does it cause bullying? J Epidemiol Community Health 2010; 64(3):202-208.

54. Archimi A, Kuntsche E. Do offenders and victims drink for different reasons? Testing mediation of drinking motives in the link between bullying subgroups and alcohol use in adolescence. Addict Behav 2014; 39(3):713-716.

55. Rivers I, Poteat VP, Noret N, Ashurst N. Observing bullying at school: the mental health implications of witness status. Sch Psychol Q 2009; 24(4):211-223.

56. Shetgiri R, Lin H, Flores G. Identifying children at risk for being bullies in the United States. Acad Pediatr 2012; 12(6):509-522.
57. Ferrett HL, Cuzen NL, Thomas KG, Carey PD, Stein DJ, Finn PR, Tapert SF, Fein G. Characterization of South African adolescents with alcohol use disorders but without psychiatric or polysubstance comorbidity. Alcohol Clin Exp Res 2011; 35(9):1705-1715.

58. Fletcher A, Bonell C, Sorhaindo A, Strange V. How might schools influence Young people's drug use? Development of theory from qualitative case-study research. J Adolesc Health 2009; 45(2):126-132.

59. Costa AB, Zoltowski APC, Koller SH, Teixeira MAP. Construção de uma escala para avaliar a qualidade metodológica de revisões sistemáticas. Cien Saude Colet 2015; 20(8):2441-2452.

60. Crookston BJ, Merrill RM, Hedges S, Lister C, West JH, Hall PC. Victimization of Peruvian adolescents and health risk behaviors: young lives cohort. BMC Public Health 2014; 14(85):1-7.

61. Kubwalo HW, Muula AS, Siziya S, Pasupulati S, Rudatsikira E. Prevalence and correlates of being bullied among in-school adolescents in Malawi: results from the 2009 Global School-Based Health Survey. Malawi Med J 2013; 25(1):12-14.

62. Siziya S, Rudatsikira E, Muula AS. Victimization from bullying among school-attending adolescents in grades 7 to 10 in Zambia. J Inj Violence Res 2012; 4(1):30-35.

63. Siziya S, Muula AS, Besa C, Babaniyi O, Songolo P, Kankiza N, Rudatsikira E. Cannabis use and its socio-demographic correlates among in-school adolescents in Zambia. Ital J Pediatr 2013; 39(13):1-5.

64. McAdams, III, Charles, R, Schmidt, CD. How to help a bully: Recommendations for counseling the proactive aggressor. Professional School Counseling 2007; 11(2):120-128.

Artigo apresentado em 07/10/2015

Aprovado em 17/12/2015

Versão final apresentada em 19/12/2015 
